\title{
Lack of serum antineuronal antibodies in children with autism
}

\author{
Bayram AK ${ }^{1}$, Kardas $\mathrm{F}^{2}$, Demirci EO ${ }^{3}$, Gokahmetoglu $\mathrm{S}^{4}$, Ozmen $\mathrm{S}^{3}$, Canpolat $\mathrm{M}^{1}$, Oztop DB ${ }^{3}$, \\ Kumandas $\mathrm{S}^{1}$, Gumus $\mathrm{H}^{1}$, Per $\mathrm{H}^{1}$ \\ Department of Pediatrics, Division of Pediatric Neurology, Erciyes University, School of Medicine, Kayseri, \\ Turkey. huseyinper@yahoo.com
}

\begin{abstract}
OBJECTIVE: Autism spectrum disorders (ASDs) are a severe group of neurodevelopmental disorders that are characterized by impairment in social communication, and imagination and social interaction. The aetiology of autism is complex, but some studies suggest autoimmunity to the central nervous system in the pathogenesis. The aim of this study is to investigate the positivity of antineuronal antibodies including anti-glutamic acid decarboxylase antibodies (anti-GAD), anti-glutamate receptor (anti-GluR) antibodies and seven types of antiganglioside antibodies, in children with autism.

METHODS: We conducted the study over a period of one year from May 2012 to December 2013. Human antiGAD in serum were investigated with ELISA; human autoantibodies against the N-methyl-D-aspartate subtype of GluR were investigated with indirect immunofluorescence test; class IgG antibodies against the seven gangliosides were investigated with immunoblot assay.

RESULTS: Serum antineuronal antibodies were measured in 42 children ( 24 male, 18 female) with autism in comparison to 21 (13 male, 8 female) healthy-matched children aged between 2-12 years. There was no seropositivity of antineuronal antibodies in either of the groups.

CONCLUSION: There is no evidence to support an association between autism and antibodies positivity of antiGAD, anti-GluR and anti-gangliosides (Ref. 26). Text in PDF www.elis.sk..

KEY WORDS: Autism, antineuronal antibodies, glutamic acid decarboxylase, glutamate receptor, ganglioside antibodies, autoimmunity.
\end{abstract}

\section{Introduction}

Autism is a neurodevelopmental disorder characterised by repetitive behaviours, stereotyped interests and impairments in social interaction, and verbal and non-verbal communication. The incidence of autism spectrum disorders (ASDs) has increased steadily over the past 15 years (1). The worldwide prevalence of autism has been reported in the studies of large-scale surveys as $1-2 \%$ (2).

Although many factors have been associated with its pathogenesis such as genetic, neurological, environmental, and immunological factors. The aetiology of ASD is not well understood, and the pathogenesis is still largely unknown (3).

Current studies suggest a significant role for immune system abnormalities and autoimmune processes in the pathogenesis. Brain specific autoantibodies were shown in children with autism and also the prevalence of autoimmune disorders was higher among autistic families (4-6). A family history of autoimmune diseases was reported in $46 \%$ of children with autism (7).

${ }^{1}$ Department of Pediatrics, Division of Pediatric Neurology, Erciyes University, School of Medicine Kayseri, Turkey, ${ }^{2}$ Department of Pediatrics, Division of Pediatric Nutrition and Metabolism, Erciyes University, School of Medicine, Kayseri, Turkey, ${ }^{3}$ Department of Child Psychiatry, Erciyes University, School of Medicine, Kayseri, Turkey, and ${ }^{4}$ Department of Microbiology, Erciyes University, School of Medicine, Kayseri, Turkey

Address for correspondence: H. Per, MD, Department of Pediatrics, Division of Pediatric Neurology, Erciyes University, School of Medicine, 38039, Kayseri, Turkey.
Glutamic acid decarboxylase (GAD) enzyme is a catalyser in the conversion of L-glutamic acid to $\gamma$-amino butyric acid (GABA), which is an inhibitory neurotransmitter (5). The relationship between autism and antibodies against GAD has been described previously (8).

Glutamate is an excitatory neurotransmitter (9). There are two main types of glutamate receptors (GluRs) including ionotropic (iGluRs) and metabotropic (mGluRs) receptors. The iGluRs are divided into three subgroups involving N-methyl-d-aspartate (NMDA), alpha-Amino-3-hydroxy-5-methyl-4-isoxazole propionic acid (AMPA), and kainite $(10,11)$. Disruption in glutamatergic signalling pathways is associated with autism and related to disorders (12).

Gangliosides play a major role in neurotransmission and memory formation. GM1 gangliosidosis is the most abundant (13). Studies report that CSF (cerebrospinal fluid) concentrations of gangliosides and blood antibodies against gangliosides are increased in children with autism $(14,15)$.

In the present study, we aimed to investigate the relation between autism and antineuronal antibodies including anti-GAD antibodies, anti-GluR antibodies, and anti-ganglioside antibodies.

\section{Methods}

\section{Study population}

A sample of 42 (24 male, 18 female) patients with autism and 21 (13 male, 8 female) control subjects were included in the study. We conducted the study over a period of one year from May 2012 to December 2013. The evaluation of the autistic patients was made 
based on clinical history, physical examination, and neuropsychiatric observation. Diagnosis of autism was confirmed by the Diagnostic and Statistical Manual of Mental Disorders, $4^{\text {th }}$ ed. (DSM-IV) (16). Children with Pervasive Developmental Disorder-Not Otherwise Specified (PDD-NOS), Asperger's Syndrome, Rett syndrome or Childhood Disintegrative disorders were not included in this study. The clinical diagnoses were made by both an experienced child psychiatrist and a child neurologist. The control group subjects showed neither laboratory nor clinical signs of other diseases, and were not related to the children with autism.

All participants were treatment-free, in good health and without diagnosis of any autoimmune disease when the blood samples were taken. The ethics committee of the Faculty of Medicine at Erciyes University approved the study protocol. Parents were given detailed written and oral information of the study aims, and they gave written consent before entering the study.

\section{Measurement of serum antibodies}

Three milllilitres of venous blood samples were collected from the patients. Sera were obtained by centrifugation at $3000 \mathrm{rpm}$ for $5 \mathrm{~min}$. The sera samples were stored at $-20{ }^{\circ} \mathrm{C}$ until the study day to maintain stability. Antibodies were investigated in the sera.

The tests were performed in the central laboratories of Erciyes University Medical Faculty. Also, all the tests were studied again in the laboratories of Ozmen A.S. Euroimmun, Turkey. The test procedure was repeated twice for each parameter.

\section{Anti-GAD antibodies}

Human anti-GAD autoantibodies in serum were investigated with ELISA(Euroimmun, Germany) according to the test procedure.

According to the manufacturer's recommendations, results $<10 \mathrm{IU} / \mathrm{Ml}$ are considered as negative, and results $\geq 10 \mathrm{IU} / \mathrm{mL}$ are considered as positive.

\section{Anti-GluR (NMDA-type) antibodies}

Human autoantibodies against GluR (NMDA-type) were investigated with indirect immunofluorescence test (Euroimmun, Germany) according to the test procedure.

The fluorescence of slides was observed with a microscope. Slides that had a fine granular cytoplasmic fluorescence, when the cell nuclei are only slightly stained, were considered as positive for autoantibodies against the GluR (NMDA-type).

\section{Anti-ganglioside antibodies}

The antibodies of class IgG against to the seven gangliosides GM1, GM2, GM3, GD1a, GD1b, GT1b and GQ1b were investigated with immunoblot assay (Euroimmun, Germany) according to the test procedure. A test strip was used in the evaluation protocol; this was air dried and then evaluated. For the evaluation of incubated test strips, Euroline scan software was used.

\section{Results}

The study sample included 42 children ( 24 male, 18 female) with autism and 21 (13 male, 8 female) control subjects. All subjects were aged between $2-12$ years. The mean ages of the autism and control groups were $5.4 \pm 2.9$ and $6.1 \pm 2.3$, respectively. The mean age when diagnosis was made was $3.5 \pm 1.7$ for the autism group. None of the 42 children with autism or 21 healthy controls had positive anti-GAD antibodies, anti-GluR antibodies, and anti-ganglioside antibodies.

Eight children with autism (19.04\%) had a first or seconddegree relative with an autoimmune disease (insulin-dependent diabetes mellitus in 4 patients, autoimmune thyroiditis in 3 patients and rheumatic fever in 1 patient). Four of the 42 children with autism $(9.52 \%)$ had a mother with an autoimmune disease (3 had insulin-dependent diabetes mellitus and 1 had autoimmune thyroiditis). On the other hand, a family history of autoimmune diseases was found in $2(9.5 \%)$ of the 21 studied healthy children ( 1 had insulin-dependent diabetes mellitus and 1 had autoimmune thyroiditis). None of the healthy children with a family history of autoimmune disease had a mother with such diseases. All patients had normal thyroid functions.

From the 42 children with autism that were included in the study, MRI scans were performed in 31 patients (73.8\%). Seventyseven percent of the MRI scans showed no abnormalities (24 patients). One patient was found to have a mega cisterna magna; one patient had a wide frontal CSF space; two patients had wide ventricles; two children had corpus callosum dysgenesia; one patient had a right temporal arachnoid cyst (total 7 patients; $23 \%$ ). Signal increases in white matter were not determined in any of the patients.

\section{Discussion}

As the pathogenesis of the autism is unclear, several possible causes have been investigated. Some evidence has demonstrated about the possible role of immune system abnormalities in the pathogenesis of ASDs in recent studies $(15,17)$. It was reported that serum antineuronal antibodies had significantly higher positivity in autistic subjects than in healthy controls $(4,18)$.

The relationship between ASD and familial autoimmunity has been known for a long time $(19,20)$. In accordance with these studies, we found out that the frequency of autoimmune diseases among the families of children with autism was higher than inthose of normal children.

Anti-GAD antibodies during gestation in the maternal blood was associated with foetal Purkinje cell loss and led to the development of autism, especially at 2-3 years of age (8).

Glutamate is the most common transmitter in the mammalian brain neurons and regulates fast-excitatory transmission (9). Some studies suggest that defects in glutamate functions in brain lead to autism. Disrupted NMDA receptors were found to be related in a number of models of ASD $(12,21)$.

Studies suggest the associations between increased CSF levels of gangliosides (GM1, GD1a, GD1b, and GT1b) and autism (13, 22). One study suggested that increased serum anti-GM1 levels were related to the severity of autism (15). Also, gangliosides were found to be higher in children with autism (18). On the other hand, Moeller et al. demonstrated that there was no association between autism and the anti-GM1 ganglioside antibody (23).

These findings motivated us to design this study to find an associ- 
ation between autism and anti-GAD antibodies, anti-GluR antibodies, and anti-ganglioside antibodies. However, our results showed negative anti-GAD antibodies in both the autistic and healthy control groups. We only analysed NMDA receptor antibodies; in contrast to other studies antibodies against NMDA, receptors were found to be negative in our study. Also, class IgG antibodies against the seven gangliosides GM1, GM2, GM3, GD1a, GD1b, GT1b and GQ1b were investigated, however, no seropositivity was found in either the autistic or in the healthy children. All the patients' sera were negative for IgG and IgM antibodies against GM1 at the lowest titres except for one patient and one healthy control in Moeller's study (23). These findings were similar with our study. This study had several limitations which could have affected our conclusion. Our study sample was limited and was not matched for gender and age.GABA levels, which were directly affected by the GAD levels, were not analysed due to lack of technical facilities. We are planning to study for GABA levels of the autistic patients in the future.

While cranial MRI is not a routine part of ASD evaluation, there have been discussions about the clinical relevance of MRI scanning in the children with autism. A wide variety of the brain abnormalities had been reported by neuroimaging studies $(24,25)$. Zeegers et al (24) found no radiological abnormalities in $50 \%$ of children with autism. Boddaert et al (25) found normal cranial MRI in $52 \%$ of non syndromic children with autism. Twenty-three percent $(7 / 31)$ of the MRI scans had abnormalities in our study. MRI scans do not have direct additional value for the diagnosis of autism. However, some findings (Chiari 1 malformations, intracranial cysts, dilated Virchow-Robin spaces, white matter signal abnormalities and corpus callosum abnormalities) may contribute to the clinical assessment of individuals with autism (24-26).

We think that autism has epigenetic and environmental reasons. Some of the common factors, which induce the development of the autism, may also cause autoimmune diseases, in contrast, other factors may induce only autism.

In conclusion, we aimed to find a relation between autism and anti-GAD antibodies, anti-GluR antibodies, and anti-ganglioside antibodies. Although we found no evidence to support an association between autism and antibodies positivity of anti-GAD, anti-GluR, and anti-gangliosides. Further studies with wider range of samples are required to clarify the association between antibodies and ASD.

\section{References}

1. Dalton R, Forman MA, Boris NW. Pervasive developmental disorders and childhood psychosis. In: Behrman, RE, Kliegman, RM, Jenson, HB, eds. Nelson textbook of Pediatrics. Philadelphia: WB Saunders; 2004, 93-94.

2. Kim YS, Leventhal BL, Koh YJ et al. Prevalence of autism spectrum disorders in a total population sample.Am J Psychiatry 2011; 168 (9): 904-1012.

3. Pop-Jordanova N, Plasevska-Karanfilska D. Autism - genetics, electrophysiology and clinical syndromes. Prilozi 2014; 35 (1): 133-146.

4. Mostafa GA, El-Hadidi ES, Hewedi DH, Abdou MM. Oxidative stress in Egyptian children with autism: relation to autoimmunity. J Neuroimmunol 2010; 219 (1-2): 114-118.

5. Dalton P, Deacon R, Blamire A et al. Maternal neuronal antibodies associated with autism and a language disorder. Ann Neurol 2003; 53 (4): 533-537.
6. Sweeten TL, Bowyer SL, Posey DJ et al. Increased prevalence of familial autoimmunity in probands with pervasive developmental disorders. Pediatrics 2003; 112 (5): e420.

7. Comi AM, Zimmerman AW, Frye VH et al. Familial clustering of autoimmune disorders and evaluation of medical risk factors in autism. J Child Neurol 1999; 14: 388-394.

8. Rout UK, Dhossche DM. A pathogenetic model of autism involving Purkinje cell loss through anti-GAD antibodies. Med Hypotheses 2008; 71 (2): 218-221.

9. Tural U, Onder E. GlutamaterjikSistem, N-Metil-D-Aspartik Asit Reseptörlerive Depresyon. Klin Psikiyatri 2002; 4: 30-34.

10. Monaghan DT, Bridges RJ, Cotman CW. The excitatory amino acid receptors: their classes, pharmacology, and distinct properties in the function of the central nervous system. Annu Rev Pharmacol Toxicol 1989; 29: 365-402.

11. Whitlock JR, Heynen AJ, Shuler MG, Bear MF. Learning induces longterm potentiation in the hippocampus. Science 2006; 313 (5790): 1093-1097.

12. Carlson GC. Glutamate receptor dysfunction and drug targets across models of autism spectrum disorders. Pharmacol Biochem Behav 2012; 100 (4): 850-854.

13. Ariga T,McDonald MP, Yu RK. Role of ganglioside metabolism in the pathogenesis of Alzheimer's disease-a review. J Lipid Res 2008; 49 (6): 1157-1175.

14. Lekman A, Skjeldal O, Sponheim E, Svennerholm L. Gangliosides in children with autism. Acta Paediatr 1995; 84 (7): 787-790.

15. Mostafa GA, Al-Ayadhi LY. Increased serum levels of anti-ganglioside M1 auto-antibodies in autistic children: relation to the disease severity. J Neuroinflamm 2011; 8: 39 .

16. American Psychiatric Association, Task Force on D-I. Diagnostic and Statistical Manual of Mental Disorders: DSM-IV-TR, American Psychiatric Association, Washington, DC, USA 2000.

17. Cohly HH, Panja A. Immunological findings in autism. Rev Neurobiol 2005; 71: 317-341.

18. Mostafa GA, Al-Ayadhi LY. The relationship between the increased frequency of serum antineuronal antibodies and the severity of autism in children. Eur J Paediatr Neurol 2012; 16 (5): 464-468.

19. Money J, Bobrow NA, Clarke FC. Autism and autoimmune disease: a family study. J Autism Child Schizophr 1971; 1: 146-160.

20. Atladottir HO, Pedersen MG, Thorsen $P$ et al. Association of family history of autoimmune diseases and autism spectrum disorders. Pediatrics 2009; 124: 687-694.

21. Eadie BD, Cushman J, Kannangara TS et al. NMDA receptor hypofunction in the dentate gyrus and impaired context discrimination in adult Fmrl knockout mice. Hippocampus 2012; 22 (2): 241-254.

22. Nordin V, Lekman A, Johansson M, Fredman P, Gillberg C. Gangliosides in cerebrospinal fluid in children with autism spectrum disorders. Dev Med Child Neurol 1998; 40 (9): 587-594.

23. Moeller S, Lau NM, Green PH, Hellberg D, Higgins JJ, Rajadhyaksha AM et al. Lack of association between autism and anti-GM1 ganglioside antibody. Neurology 2013; 81 (18): 1640-1641.

24. Zeegers M, Van Der Grond J, Durston S, Nievelstein RJ, Witkamp T, Van Daalen E et al. Radiological findings in autistic and developmentally delayed children. Brain Dev 2006; 28 (8): 495-499.

25. Boddaert N, Zilbovicius M, Philipe A, Robel L, Bourgeois M, Barthélemy $\mathrm{C}$ et al. MRI findings in 77 children with non-syndromic autistic disorder. PLoS One 2009; 4 (2): e4415.

26. Jayarao M, Sohl K, Tanaka T. Chiari malformation I and autism spectrum disorder: an under recognized coexistence. J Neurosurg Pediatr 2015; 15 (1): 96-100. 